\title{
Ketcher: web-based chemical structure editor
}

\author{
B Karulin", M Kozhevnikov \\ From 6th German Conference on Chemoinformatics, GCC 2010 \\ Goslar, Germany. 7-9 November 2010
}

Ketcher is an open-source web-based chemical structure editor developed by SciTouch LLC. Being written on pure JavaScript it incorporates high performance, good portability and light weight. Editor supports late versions of all most popular browsers, such as Internet Explorer, Firefox, Safari, Opera and Chrome.

It is developed with minimum third-party code to remain its light weight. It is platform-independent and can be used as a structure viewer as well. SciTouch keeps on working to add more features to Ketcher in near future.

Ketcher is available under Affero GPL license.

Features:

- Standalone mode. Ketcher supports standalone mode in which no server support is required.

- Scalable Vector Graphics (SVG) for rendering. Ketcher uses SVG to achieve the best quality of inbrowser chemical structure rendering. SVG standard is supported by most of modern browsers and provides smooth and light-weight drawing. IE rendering is based on VML (Vector Markup Language) instead.

- SMILES strings. SMILES is a compact format for chemical structure representation. Ketcher gives you ability to load and save structure in this useful format.

- Automatic layout (clean up). Server-side structure layout is implemented basing on Indigo cheminformatics library with a Python wrapper. Indigo provides fast 2D structure representation which satisfies common chemical drawing standards.

- And also: MDL (Symyx) molfiles support, hot keys, stereochemistry support, complete undo/redo history and much more.

Ketcher web site: http://scitouch.net/ketcher

Try Ketcher demo: http://scitouch.net/ketcher-demo/ ketcher.html

Published: 19 April 2011

* Correspondence: karulin@scitouch.net

SciTouch LLC, St.-Petersburg, Russia

Full list of author information is available at the end of the article

doi:10.1186/1758-2946-3-S1-P3

Cite this article as: Karulin and Kozhevnikov: Ketcher: web-based

chemical structure editor. Journal of Cheminformatics 2011 3(Suppl 1):P3. \begin{tabular}{l}
$\begin{array}{l}\text { Publish with ChemistryCentral and every } \\
\text { scientist can read your work free of charge } \\
\text { "Open access provides opportunities to our } \\
\text { colleagues in other parts of the globe, by allowing } \\
\text { anyone to view the content free of charge." } \\
\text { W. Jeffery Hurst, The Hershey Company. } \\
\text { - available free of charge to the entire scientific community } \\
\text { - peer reviewed and published immediately upon acceptance } \\
\text { - cited in PubMed and archived on PubMed Central } \\
\text { - yours - you keep the copyright } \\
\text { Submit your manuscript here: } \\
\text { htp:///www.chemistrycentral.com/manuscript }\end{array}$ \\
\hline
\end{tabular} 